\title{
FITOSSOCIOLOGIA DAS PLANTAS DANINHAS NA CULTURA DO BACURI (Platonia insignis MART.) NA AMAZÔNIA ORIENTAL
}

\author{
Cíntia Leticia Monteiro do Carmoํㅗㄹ Mariana Casari Parreira², Jefferson dos Santos Martins², Rafael \\ Coelho Ribeiro², Evaldo Morais da Silva²
}

\begin{abstract}
RESUMO - Na Amazônia Oriental, além da agricultura familiar, há a predominância do extrativismo de diversas espécies vegetais que servem de base para a economia familiar, dentre elas podemos destacar o bacuri. Um dos fatores que afetam a produtividade das plantas de bacuri, são as plantas daninhas que por fatores bióticos reduzem a produção competindo por água, luz, nutrientes, $\mathrm{CO}_{2}$ e $\mathrm{O}_{2}$. O objetivo do trabalho foi avaliar a comunidade infestante, na cultura do bacuri em diferentes estágios de desenvolvimento, na Amazônia Tocantina. O estudo foi realizado em uma área de um hectare de bacurizeiros nativos, de oito a 10 anos de idade. As avaliações foram realizadas em quatro estágios de desenvolvimento da planta de bacuri (florescimento, formação do fruto, colheita e pós-colheita dos frutos). Verificou-se que a composição da flora infestante não foi idêntica em todas as avaliações durante o período experimental. Contudo, as espécies Rhynchospora cephalotes, Heliconia angusta e Eugenia punicifolia foram as mais relevantes na área experimental.
\end{abstract}

Palavras chave: comunidade infestante, extrativismo, Platonia insignis Mart.

\section{WEED PHYTOSOCIOLOGY IN Platonia insignis MART. ON AMAZONIA ORIENTAL}

\begin{abstract}
The family agriculture on Amazonia Oriental, there is a predominance of extractivism of several vegetable species that serve as a basis for the family economy, among which we can highlight Platonia insignis. One of the factors that affect Platonia insignis crop is the weeds reducing production, competing for water, light, nutrients, $\mathrm{CO}_{2}$ and $\mathrm{O}_{2}$. The objective of this work is to evaluate the weed community, on Platonia insignis crop at different stages of development on Amazonia Oriental. The study was conducted in an area of one hectare of native plants. The evaluations were carried out in four stages of development of the plant (flowering, fruit formation, harvesting and post-harvesting of fruits). It was found that the weed flora composition was not identical at all evaluations during the experimental period. However, the species Rhynchospora cephalotes, Heliconia angusta and Eugenia punicifolia were the most relevant in the experimental area.
\end{abstract}

Keywords: adaptation, sabiá, semi-arid.

\footnotetext{
${ }^{1}$ Universidade Tecnológica Federal do Paraná (UTFPR) (cintialeticia12@gmail.com), Faculdade de Agronomia (FAGRO).

${ }^{2}$ Campus Universitário do Tocantins; Universidade Federal do Pará. CUNTINS-UFPA. Cameta-PA. (mcparreira@ufpa.br; santos-jeff@hotmail.com; rribeiro@ufpa.br; evaldomorais@ufpa.br )
} 


\section{INTRODUÇÃO}

Na Amazônia Oriental, além da agricultura familiar, tem-se a predominância do extrativismo de diversas espécies vegetais que servem de base para a economia familiar (Homma, 2012). Dentre as quais o bacuri, fruto do bacurizeiro (Platonia insignis Mart.).

O bacurizeiro é uma planta de grande porte utilizada na indústria madeireira e alimentícia. Seus frutos contêm polpa agridoce rica em nutrientes, podendo ser consumida in natura ou utilizada para a produção de doces, sorvetes, sucos, geleias, licores entre outras iguarias. Sua casca é também aproveitada na culinária regional e o óleo extraído de suas sementes é usado como anti-inflamatório e cicatrizante na medicina popular e na indústria de cosméticos (Homma et al., 2010).

Contudo, existem fatores limitantes como a presença de populações de plantas daninhas na área de cultivo que podem interferir de maneira direta ou mesmo indireta na produção do bacuri. Como prenunciado, a comunidade infestante, definida como o conjunto de todas as populações de plantas daninhas que habitam um determinado meio ou área em função de um objetivo específico de estudo, são agentes bióticos que comprometem negativamente a produção através da competição com a cultura principal (Pitelli, 2015).

A competição traduz as relações de concorrência existentes entre as plantas que vivem em comunidade, na disputa por fatores fundamentais para o crescimento como: água, luz, nutrientes, $\mathrm{CO}_{2}$ e $\mathrm{O}_{2}$ (Brighenti \& Oliveira, 2011). Nesse contexto, uma das formas de se analisar o impacto que os sistemas de manejo exercem sobre o crescimento e ocupação das comunidades infestantes é através de índices fitossociológicos (Oliveira \& Freitas, 2008), que comparam as populações de plantas daninhas em um determinado tempo e espaço visando designar as espécies mais representativas decorrentes nas áreas em produção (Carvalho et al., 2008).

Desse modo, o levantamento fitossociológico resulta em uma lista de espécies distribuídas de forma hierarquizadas, em função da sua posição relativa às demais, permitindo a interpretação quantitativa e as relações ecológicas da comunidade infestante (Gama, 2009). Assim sendo, o objetivo deste trabalho foi avaliar a comunidade infestante, na cultura do bacuri em diferentes estágios de desenvolvimento, na Amazônia Oriental.

\section{MATERIAL E MÉTODOS}

O estudo foi realizado em uma área (1 ha) com bacurizeiros nativos entre oito a dez anos de idade, em uma propriedade rural localizada no município de Cametá (02¹2’14,7" S e 49²8’31,9" O), estado do Pará.

Foram realizadas quatro avaliações, das plantas daninhas presentes na área, nos seguintes estágios de desenvolvimento do bacurizeiro: florescimento, formação do fruto, colheita e pós-colheita dos frutos.

Para a avaliação da comunidade infestante, em todas as épocas avaliadas, foram tomadas oito áreas amostrais distintas de $1 \mathrm{~m}^{2}$, onde as plantas daninhas presentes foram removidas, separadas por espécie, contadas, secas ao ar e pesadas com o auxílio de uma balança para a determinação da massa seca.

Posteriormente, as plantas coletadas foram identificadas mediante consultas a especialistas do museu Emilio Goeldi (Belém-PA) e trabalhos científicos relacionados. Durante todo o período experimental foram coletadas informações sobre precipitação pluviométrica e temperaturas, exemplificadas na Figura 1.

A partir das informações coletadas das espécies presentes na área, foram calculados os índices fitossociológicos: densidade (Den), densidade relativa (DenR), frequência (Fre), frequência relativa (FreR), abundância (Abu), abundância relativa (AbuR), índice de valor de importância (IVI), índice de valor de importância relativo (IR).

Para o cálculo das variáveis foram utilizadas as seguintes equações:

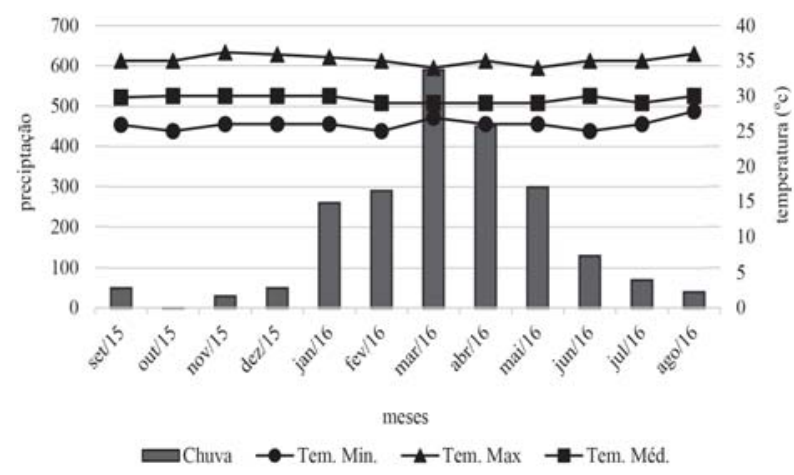

Figura 1 - Dados médios de temperaturas (mínima, máxima e média) e precipitação durante a fase experimental.

Fonte: INMET (2016). 


$$
\begin{gathered}
\text { Den }\left(\text { plantas. } \mathrm{m}^{2}\right)=\frac{\mathrm{N}^{\circ} \text { total de individuos por especie }}{\text { Area total coletada }} \\
\text { DenR }(\%)=\frac{\text { Densidade da especie } \times 100}{\text { Densidade total de totas as especies }} \\
\text { Fre }=\frac{\text { № de parcelas que contem a especie }}{\text { № total de amostras utilizadas }} \\
\text { FreR }(\%)=\frac{\text { Frequencia da especie } \times 100}{\text { Frequencia total de totas as especies }} \\
\text { Abu }=\frac{\text { № total de individuos por especie }}{\text { № total de parcelas contendo a especies }} \\
\text { AbuR (\%) }=\frac{\text { Abundância da especie } \times 100}{\text { Abundância total de totas as especies }} \\
\text { IVI }=\text { Frr. Der . Abr . Mfr } \\
\text { IR (\%) }=\frac{\text { IVI } \times 100}{\text { IVI total de totas as especies }}
\end{gathered}
$$

\section{RESULTADOS E DISCUSSÃO}

Em todo o período experimental foram encontradas 1.502 plantas infestantes, com 53 espécies, distribuídas em 35 famílias botânicas (Tabela 1). As eudicotiledoneas foram as mais encontradas com $88 \%$, sendo a família Lauraceae a mais representativa, com cinco espécies, representando 9,43\% do total de espécies encontradas.

As monocotiledôneas foram encontradas em menor número, com $11,42 \%$ das espécies, tendo as famílias Poaceae e Cyperaceae, como as mais representativas, com três espécies cada. De acordo com Sandre et al. (2008), as plantas eudicotiledôneas são mais diversificadas e incluem quase todas as árvores, arbustos e ervas e por isso englobam a maioria das espécies, com cerca de 150 mil.

A composição da flora infestante foi distinta durante todo o período experimental, de acordo com as épocas avaliadas (estágio das plantas de bacuri), exemplificado a seguir:

\section{Formação do fruto}

A comunidade infestante nesta época foi avaliada quando os bacurizeiros se encontravam em plena formação de fruto. As três espécies mais relevantes encontradas na área foram Heliconia angusta,
Rhynchospora cephalotes e Dimerocostus strobilaceus (Tabela 2). Estas espécies atingiram os maiores valores na maioria dos índices avaliados, exceto frequência (Fre) e frequência relativa (FreR), no qual a espécie Eugenia punicifolia obteve os maiores valores, com 4 e $8,89 \%$ respectivamente.

Em conformidade com Sobral et al. (2010), pertencente à família Myrtaceae, a espécie E. punicifolia é tradicionalmente utilizada como planta medicinal, sendo encontrada em grande parte das regiões do Brasil.

A espécie $H$. angusta superou as demais em todos os índices, atingindo em 16\% o índice de importância relativa (IR) (Tabela 2), sendo superior a 21,6\% da segunda colocada ( $R$. cephalotes), que obteve IR de $12,72 \%$. Nativa do Brasil, a espécie $H$. angusta desenvolvese facilmente em condições climáticas baixas com pouco sombreamento, em virtude disso é normalmente encontrada no sudeste brasileiro e tem sua utilização voltada para o corte de flor (De Castro et al., 2011a).

A espécie D. strobilaceus (terceira mais representativa neste estudo), atingiu o índice de valor de importância (IVI) acima de 41 e importância relativa (IR) de 10,33\% (Tabela 2). Apesar da tendência para o paisagismo e jardinagem, esta espécie do gênero Dimerocostus, pertencente à família Costaceacea que apresenta ampla difusão continental, ainda é pouco explorada economicamente (De Castro et al., 2011b).

\section{Colheita}

Nesta época de avaliação, os bacurizeiros se encontravam em plena colheita, e foram encontradas na comunidade infestante as espécies Rhynchospora cephalotes, Tradescantia crassula e Eugenia punicifolia como as mais relevantes, obtendo os mais altos valores, na maioria dos índices avaliados (Tabela 3). Entretanto ao avaliar a frequência (Fre) e frequência relativa (FreR), a espécie Gibasis geniculata se destacou, atingindo valores de 4 e 11,76\% respectivamente, sendo esses valores muito próximos ao da terceira espécie mais importante a E. punicifolia, que nesta avaliação atingiu valores de 5 e 14,71\% na frequência (Fre) e frequência relativa (FreR), respectivamente.

A espécie G. geniculata pertencente à família Commelinaceae, muito presente no norte do Brasil, pode causar grandes prejuízos econômicos nas culturas agrícolas, como soja, milho, pomares de laranja, cafezais, devido a sua alta agressividade (Rocha et al., 2000). 
Tabela 1 - Descrição da distribuição das plantas daninhas coletadas na área durante o todo período experimental, Amazônia Oriental - PA

\begin{tabular}{|c|c|c|}
\hline Família & Nome científico & \\
\hline \multirow[t]{5}{*}{ Lauraceae } & Misanteca mahuba (A.Samp.) Lundell & Eudicotiledônea \\
\hline & Cinnamomum sellowianum (Nees \& Mart.) Kosterm. & Eudicotiledônea \\
\hline & Cassytha americana Nees & Eudicotiledônea \\
\hline & Cryptocarya aschersoniana Mez & Eudicotiledônea \\
\hline & Endlicheria paniculata (Spreng.) J.F.Macbr. & Eudicotiledônea \\
\hline \multirow[t]{4}{*}{ Fabaceae } & Aeschynomene brevifolia L. ex Poir. & Eudicotiledônea \\
\hline & Inga lateriflora Miq. & Eudicotiledônea \\
\hline & Inga alba (Sw.) Willd. & Eudicotiledônea \\
\hline & Dioclea virgata (Rich.) Amshoff var. virgata & Eudicotiledônea \\
\hline \multirow[t]{3}{*}{ Cyperaceae } & Rhynchospora cephalotes (L.) Vahl & Monocotiledônea \\
\hline & Rhynchospora ciliata (Vahl) Kük. & Monocotiledônea \\
\hline & Cyperus iria L. & Monocotiledônea \\
\hline \multirow[t]{3}{*}{ Poaceae } & Trachypogon spicatus (L.f.) Kuntze & Monocotiledônea \\
\hline & Paspalum pilosum Lam. & Monocotiledônea \\
\hline & Pariana sp. Aubl. & Monocotiledônea \\
\hline \multirow[t]{2}{*}{ Myrtaceae } & Eugenia punicifolia (Kunth) DC. & Eudicotiledônea \\
\hline & Myrcia splendens (Sw.) DC. & Eudicotiledônea \\
\hline \multirow[t]{2}{*}{ Heliconiceae } & Heliconia psittacorum L.f. & Monocotiledônea \\
\hline & Heliconia angusta Vell. & Monocotiledônea \\
\hline \multirow{2}{*}{ Commelinaceae } & Tradescantia crassula Link \& Otto & Monocotiledônea \\
\hline & Gibasis geniculata (Jacq.) Rohweder & Monocotiledônea \\
\hline \multirow[t]{2}{*}{ Canellaceae } & Cinnamodendron dinisiin Schwacke & Eudicotiledônea \\
\hline & Cinnamodendron axillare Endl. ex Walp. & Eudicotiledônea \\
\hline \multirow{2}{*}{ Euphorbiaceae } & Astraea lobata (L.) Klotzsch & Eudicotiledônea \\
\hline & Euphorbia heterophylla L. & Eudicotiledônea \\
\hline \multirow[t]{2}{*}{ Asteraceae } & Mikania cordifolia (L.f.) Willd. & Eudicotiledônea \\
\hline & Solidago chilensis Meyen & Eudicotiledônea \\
\hline \multirow{2}{*}{ Olacaceae } & Tetrastylidium grandifolium (Baill.) Sleumer & Eudicotiledônea \\
\hline & Minquartia guianensis Aubl. & Eudicotiledônea \\
\hline Malvaceae & Waltheria americana $\mathrm{L}$. & Eudicotiledônea \\
\hline Nyctaginaceae & Guapira parvifolia (Standl.) Lundell & Eudicotiledônea \\
\hline Melastomataceae & Clidemia hirta (L.) D.Don & Eudicotiledônea \\
\hline Hypericaceae & Vismia guianensis (Aubl.) Choisy & Eudicotiledônea \\
\hline Humiriaceae & Sacoglottis guianensis Benth. & Eudicotiledônea \\
\hline Dichapetalaceae & Dichapetalum rugosum (Vahl) Prance & Eudicotiledônea \\
\hline Gentianaceae & Chelonanthus purpurascense (Abul.) Struwe et al. & Eudicotiledônea \\
\hline Rubiaceae & Spermacoce ocymifolia Willd. ex Roem. \& Schult. & Eudicotiledônea \\
\hline Bignoniaceae & Amphilophium magnolifolium (Kunth) L.G.Lohmann & Eudicotiledônea \\
\hline Costaceae & Dimerocostus strobilaceus Kuntze & Eudicotiledônea \\
\hline Cecropiaceae & Cecropia pachystachya Trécul. & Eudicotiledônea \\
\hline Violaceae & Paypayrola grandiflora Tul. & Eudicotiledônea \\
\hline Plantaginaceae & Angelonia campestris Nees \& Mart. & Eudicotiledônea \\
\hline Chrysobalanaceae & Parinari obtusifolia Hook. f. & Eudicotiledônea \\
\hline Salicaceae & Banara nítida Spruce ex Benth. & Eudicotiledônea \\
\hline Phyllanthaceae & Phyllanthuis niruri L. & Eudicotiledônea \\
\hline Amaranthaceae & Alternanthera brasiliana (L.) Kuntze & Eudicotiledônea \\
\hline Monimiaceae & Hennecartia omphalande & Eudicotiledônea \\
\hline Hydrocharitaceae & Egeria najas Planch. & Eudicotiledônea \\
\hline Menispermaceae & Orthomene schomburgkii (Miers) Barneby \& Krukoff & Eudicotiledônea \\
\hline Marantaceae & Ischnosiphon obliquus (Rudge) Körn & Eudicotiledônea \\
\hline Brassicaceae & Tarenaya spinosa (Jacq.) Raf. & Eudicotiledônea \\
\hline Lythraceae & Rotala ramosior (L.) Koehne & Eudicotiledônea \\
\hline Opiliaceae & Agonandra excelsa Griseb. & Eudicotiledônea \\
\hline
\end{tabular}


Tabela 2 - Descrição dos índices fitossociológicos da comunidade infestante, na época de formação dos frutos do bacurizeiro, Amazônia Oriental - PA

\begin{tabular}{|c|c|c|c|c|c|c|c|c|}
\hline Espécies & Den & $\begin{array}{c}\text { DenR } \\
(\%)\end{array}$ & Fre & $\begin{array}{c}\text { FreR } \\
(\%)\end{array}$ & Abu & $\begin{array}{c}\text { AbuR } \\
\text { (\%) }\end{array}$ & IVI & $\begin{array}{l}\text { IR } \\
\text { (\%) }\end{array}$ \\
\hline Heliconia angusta & 15,38 & 22,65 & 2 & 4,44 & 61,5 & 21,45 & 64,79 & 16,20 \\
\hline Rhynchospora cephalotes & 10,75 & 15,84 & 2 & 4,44 & 43 & 15 & 50,87 & 12,72 \\
\hline Dimerocostus strobilaceues & 11,88 & 17,50 & 3 & 6,67 & 31,67 & 11,05 & 41,31 & 10,33 \\
\hline Gibasis geniculata & 6 & 8,84 & 2 & 4,44 & 24 & 8,37 & 39,76 & 9,94 \\
\hline Borreria ocymifolia & 6,13 & 9,02 & 2 & 4,44 & 24,5 & 8,55 & 24,67 & 6,17 \\
\hline Rhynchospora ciliata & 3,13 & 4,60 & 1 & 2,22 & 25 & 8,72 & 21,01 & 5,25 \\
\hline Trachypogon spicatus & 3 & 4,42 & 2 & 4,44 & 12 & 4,19 & 18,44 & 4,61 \\
\hline Eugenia punicifolia & 2,75 & 4,05 & 4 & 8,89 & 5,5 & 1,92 & 16,15 & 4,04 \\
\hline Tradescantia crassula & 1,5 & 2,21 & 2 & 4,44 & 6 & 2,09 & 14,64 & 3,66 \\
\hline Inga alba & 1 & 1,47 & 2 & 4,44 & 4 & 1,40 & 10,83 & 2,71 \\
\hline Vismia guianensis & 0,88 & 1,29 & 1 & 2,22 & 7 & 2,44 & 10,84 & 2,71 \\
\hline Dichapetalum rugosum & 0,13 & 0,18 & 1 & 2,22 & 1 & 0,35 & 7,14 & 1,78 \\
\hline Sacoglottis guianensis & 0,13 & 0,18 & 1 & 2,22 & 1 & 0,35 & 6,13 & 1,53 \\
\hline Paspalum pilosum & 0,63 & 0,92 & 1 & 2,22 & 5 & 1,74 & 5,89 & 1,47 \\
\hline Cecropia pachystachya & 0,63 & 0,92 & 1 & 2,22 & 5 & 1,74 & 5,82 & 1,46 \\
\hline Inga lateriflora & 0,63 & 0,92 & 1 & 2,22 & 5 & 1,74 & 5,61 & 1,40 \\
\hline Amphilophium magnoliifolium & 0,63 & 0,92 & 1 & 2,22 & 5 & 1,74 & 5,46 & 1,37 \\
\hline Heliconia psittacorum & 0,25 & 0,37 & 2 & 4,44 & 1 & 0,35 & 5,45 & 1,36 \\
\hline Guapira parvifolia & 0,13 & 0,18 & 2 & 4,44 & 0,5 & 0,17 & 4,95 & 1,24 \\
\hline Waltheria americana & 0,38 & 0,55 & 1 & 2,22 & 3 & 1,05 & 3,96 & 0,99 \\
\hline Aeschynomene brevifolia & 0,25 & 0,37 & 1 & 2,22 & 2 & 0,70 & 3,93 & 0,98 \\
\hline Cyperus iria & 0,13 & 0,18 & 1 & 2,22 & 1 & 0,35 & 3,55 & 0,89 \\
\hline Angelonia campetris & 0,25 & 0,37 & 1 & 2,22 & 2 & 0,70 & 3,58 & 0,89 \\
\hline Dioclea virgata & 0,25 & 0,37 & 1 & 2,22 & 2 & 0,70 & 3,43 & 0,86 \\
\hline Paypayrola grandiflora & 0,25 & 0,37 & 1 & 2,22 & 2 & 0,70 & 3,43 & 0,86 \\
\hline Astraea lobata & 0,25 & 0,37 & 1 & 2,22 & 2 & 0,70 & 3,43 & 0,86 \\
\hline Cinnamodendron dinisii & 0,13 & 0,18 & 1 & 2,22 & 1 & 0,35 & 3,33 & 0,83 \\
\hline Myrcia splendens & 0,13 & 0,18 & 1 & 2,22 & 1 & 0,35 & 2,90 & 0,72 \\
\hline Clidemia hirta & 0,13 & 0,18 & 1 & 2,22 & 1 & 0,35 & 2,90 & 0,72 \\
\hline Chelonanthus purpurascense & 0,13 & 0,18 & 1 & 2,22 & 1 & 0,35 & 2,90 & 0,72 \\
\hline Misanteca mahuba & 0,13 & 0,18 & 1 & 2,22 & 1 & 0,35 & 2,90 & 0,72 \\
\hline TOTAL & 67,88 & 100 & 45 & 100 & 286,67 & 100 & 400,00 & 100 \\
\hline
\end{tabular}

Den: densidade (pl/ $\left.\mathrm{m}^{-2}\right)$; Fre: frequência; Abu: abundância, DenR: densidade relativa (\%); FreR: frequência relativa (\%); AbuR: abundância relativa (\%); IVI: índice de valor de importância; IR: importância relativa (\%).

A espécie $R$. cephalotes continuou com grande relevância, com os maiores índices de densidade (Den) $(14,38)$, densidade relativa (DenR) (25,73\%), frequência (Fre) (6), frequência relativa (FreR) (17,65\%), índice de valor de importância (IVI) $(89,82)$ e importância relativa IR (22,45\%).

Na produção agrícola, a incidência das Cyperaceas, na qual pertence à espécie $R$. cephalotes, prejudicam intensamente várias culturas, em entorno de 89\% para alho, $81 \%$ para feijão e $79 \%$ para a cultura do milho, entre outras, sendo difícil o controle dessas plantas, principalmente pela aplicação de métodos isolados de controle, seja mecânico ou químico (Silva et al., 2002).
Outra espécie que foi muito relevante nesta avaliação foi a T. crassula, possuindo altos valores de abundância (Abu), abundância relativa (AbuR) e índice de valor de importância relativa (IVI), sendo 22; 14,62 e 85,89 respectivamente, acarretando em uma importância relativa de (IR) de 21,47 , no que se assemelhou com a planta mais relevante desta avaliação a $R$. cephalotes, que possuiu $22,45 \%$ de importância relativa (IR).

O gênero Tradescantia, na qual a espécie T. crassula (taboquinha-roxa) pertence, é muito utilizado em ornamentação por todo o país, sendo de fácil cultivo e propagação, possui alta resistência aos fatores 
Tabela 3 - Descrição dos índices fitossociológicos da comunidade infestante, na época de colheita dos frutos do bacurizeiro, Amazônia Oriental - PA

\begin{tabular}{|c|c|c|c|c|c|c|c|c|}
\hline Espécies & Den & $\begin{array}{c}\text { DenR } \\
(\%)\end{array}$ & Fre & $\begin{array}{c}\text { FreR } \\
(\%)\end{array}$ & Abu & $\begin{array}{c}\text { AbuR } \\
(\%)\end{array}$ & IVI & $\begin{array}{l}\text { IR } \\
(\%)\end{array}$ \\
\hline Rhynchospora cephalotes & 14,38 & 25,73 & 6 & 17,65 & 19,17 & 12,74 & 89,82 & 22,45 \\
\hline Tradescantia crassula & 8,25 & 14,77 & 3 & 8,82 & 22,00 & 14,62 & 85,89 & 21,47 \\
\hline Eugenia punicifolia & 14,88 & 26,62 & 5 & 14,71 & 23,80 & 15,82 & 59,27 & 14,82 \\
\hline Paspalum pilosum & 8,38 & 14,99 & 2 & 5,88 & 33,50 & 22,26 & 50,82 & 12,71 \\
\hline Gibasis geniculata & 2,25 & 4,03 & 4 & 11,76 & 4,50 & 2,99 & 21,56 & 5,39 \\
\hline Solidago chilensis & 2,50 & 4,47 & 2 & 5,88 & 10,00 & 6,65 & 17,65 & 4,41 \\
\hline Inga lateriflora & 1,63 & 2,91 & 1 & 2,94 & 13,00 & 8,64 & 15,97 & 3,99 \\
\hline Euphorbia heterophylla & 1,25 & 2,24 & 1 & 2,94 & 10,00 & 6,65 & 12,29 & 3,07 \\
\hline Vismia guianensis & 0,63 & 1,12 & 2 & 5,88 & 2,50 & 1,66 & 9,31 & 2,33 \\
\hline Hennecartia omphalande & 0,50 & 0,89 & 2 & 5,88 & 2,00 & 1,33 & 8,29 & 2,07 \\
\hline Phyllanthus niruri & 0,38 & 0,67 & 1 & 2,94 & 3,00 & 1,99 & 6,62 & 1,66 \\
\hline Banara nítida & 0,38 & 0,67 & 1 & 2,94 & 3,00 & 1,99 & 5,98 & 1,49 \\
\hline Mikania cordifolia & 0,13 & 0,22 & 1 & 2,94 & 1,00 & 0,66 & 4,39 & 1,10 \\
\hline Alternanthera brasiliana & 0,13 & 0,22 & 1 & 2,94 & 1,00 & 0,66 & 4,20 & 1,05 \\
\hline Parinari obtusifolia & 0,13 & 0,22 & 1 & 2,94 & 1,00 & 0,66 & 4,01 & 1,00 \\
\hline Cinnamomum sellowianum & 0,13 & 0,22 & 1 & 2,94 & 1,00 & 0,66 & 3,92 & 0,98 \\
\hline TOTAL & 55,88 & 100 & 34 & 100 & 150,47 & 100 & 400 & 100 \\
\hline
\end{tabular}

Den: densidade (pl/ $\left.\mathrm{m}^{-2}\right)$; Fre: frequência; Abu: abundância, DenR: densidade relativa (\%); FreR: frequência relativa (\%); AbuR: abundância relativa (\%); IVI: índice de valor de importância; IR: importância relativa (\%).

climáticos e ambientais, assim sendo facilmente propagada vegetativamente (Savóia, 2007).

Nesta avaliação a espécie Paspalum pilosum, foi relevante no índice de abundância (Abu) e abundância relativa (AbuR), possuindo altos valores com 33,50 e 22,26\% respectivamente. Segundo Maciel et al. (2009), a espécie $P$. pilosum faz parte de um dos maiores gêneros da família Poaceae e engloba um grande número de espécies invasoras (Ferreira et al., 2009).

Segundo Reis (2013), P. pilosum possui hábito decumbente, ou seja, apresenta bom desenvolvimento inicial, se prostrando ao solo e fechando-o por completo, sendo esta uma característica capaz de impedir o desenvolvimento de espécies circunscritas no mesmo espaço (Reis, 2013).

\section{Pós-colheita}

Esta avaliação ocorreu após os frutos das árvores de bacuri serem colhidos. As espécies Rhynchospora cephalotes e Eugenia punicifolia lideraram todos os índices, porém surgindo uma nova espécie, como terceira mais relevante Inga lateriflora (Tabela 4). Mesmo essa espécie não sendo relevante nas demais épocas avaliadas, nesta época de avaliação ela figurou com altos valores na maioria dos índices.
De acordo com Souza et al. (2005), são conhecidas cerca de 300 espécies do gênero Inga, sendo o seu centro de origem na floresta amazônica, mas o gênero possui representantes no México, Antilhas e em toda a América do Sul, sendo exclusivamente neotropical, que em geral, desenvolvem-se às margens dos rios, devido à grande quantidade de sementes levadas e depositadas nas várzeas pelas enchentes.

A espécie $R$. cephalotes novamente obteve os maiores valores em todos os índices, com 14,63 em densidade (Den); 43,66\% em densidade relativa (DenR); 4 em frequência (Fre); 11,8\% em frequência relativa (FreR); 29,20 em abundância (Abu); 22,36\% em abundância relativa (AbuR) e 120,31 no índice de valor de importância (IVI) (sendo neste índice o maior valor encontrado durante todo o experimento), no que culminou em 30,08\% de importância relativa (IR) (Tabela 4).

A espécie E. punicifolia, foi a segunda mais importante, com 5,75 em densidade (Den); 17,16\% em densidade relativa (DenR); 3 em frequência (Fre); 8,8\% em frequência relativa (FreR); 15,30 em abundância (Abu); 11,72\% em abundância relativa (AbuR) e 41,99 no índice de valor de importância IVI, gerando 10,5\% na importância relativa (IR). 
Tabela 4 - Descrição dos índices fitossociológicos da comunidade infestante, na época de pós-colheita dos frutos de bacurizeiro, Amazônia Oriental - PA

\begin{tabular}{|c|c|c|c|c|c|c|c|c|}
\hline Espécies de plantas daninhas & Den & $\begin{array}{c}\text { DenR } \\
(\%)\end{array}$ & Fre & $\begin{array}{c}\text { FreR } \\
(\%)\end{array}$ & Abu & $\begin{array}{c}\text { AbuR } \\
(\%)\end{array}$ & IVI & $\begin{array}{l}\text { IR } \\
(\%)\end{array}$ \\
\hline Rhynchospora cephalotes & 14,63 & 43,66 & 4 & 11,8 & 29,2 & 22,36 & 120,31 & 30,08 \\
\hline Eugenia punicifolia & 5,75 & 17,16 & 3 & 8,8 & 15,3 & 11,72 & 41,99 & 10,50 \\
\hline Inga lateriflora & 2,88 & 8,58 & 1 & 2,9 & 23,0 & 17,58 & 30,04 & 7,51 \\
\hline Pariana sp. & 1,88 & 5,60 & 4 & 11,8 & 3,75 & 2,87 & 29,32 & 7,33 \\
\hline Vismia guianensis & 1,50 & 4,48 & 1 & 2,9 & 12,0 & 9,17 & 21,92 & 5,48 \\
\hline Ischnosiphon obliquus & 0,88 & 2,61 & 2 & 5,9 & 3,50 & 2,68 & 18,38 & 4,59 \\
\hline Trachypogon spicatus & 0,63 & 1,87 & 1 & 2,9 & 5,00 & 3,82 & 16,26 & 4,06 \\
\hline Minquartia guianensis & 0,63 & 1,87 & 1 & 2,9 & 5,00 & 3,82 & 14,79 & 3,70 \\
\hline Rotala ramosior & 1,00 & 2,99 & 1 & 2,9 & 8,00 & 6,11 & 12,56 & 3,14 \\
\hline Cinnamodendron axillare & 0,50 & 1,49 & 1 & 2,9 & 4,00 & 3,06 & 11,57 & 2,89 \\
\hline Rhynchospora ciliata & 0,75 & 2,24 & 2 & 5,9 & 3,00 & 2,29 & 11,25 & 2,81 \\
\hline Heliconia psittacorum & 0,25 & 0,75 & 2 & 5,9 & 1,00 & 0,76 & 8,44 & 2,11 \\
\hline Endlicheria paniculata & 0,38 & 1,12 & 1 & 2,9 & 3,00 & 2,29 & 7,92 & 1,98 \\
\hline Agonandra excelsa & 0,25 & 0,75 & 1 & 2,9 & 2,00 & 1,53 & 7,10 & 1,77 \\
\hline Tetrastylidium grandifolium & 0,25 & 0,75 & 1 & 2,9 & 2,00 & 1,53 & 6,57 & 1,64 \\
\hline Tarenaya spinosa & 0,25 & 0,75 & 1 & 2,9 & 2,00 & 1,53 & 6,16 & 1,54 \\
\hline Cryptocarya aschersoniana & 0,25 & 0,75 & 1 & 2,9 & 2,00 & 1,53 & 5,84 & 1,46 \\
\hline Clidemia hirta & 0,13 & 0,37 & 1 & 2,9 & 1,00 & 0,76 & 5,54 & 1,39 \\
\hline Inga alba & 0,25 & 0,75 & 1 & 2,9 & 2,00 & 1,53 & 5,43 & 1,36 \\
\hline Sacoglottis guianensis & 0,13 & 0,37 & 1 & 2,9 & 1,00 & 0,76 & 5,02 & 1,25 \\
\hline Orthomene schomburgkii & 0,13 & 0,37 & 1 & 2,9 & 1,00 & 0,76 & 5,02 & 1,25 \\
\hline Egeria najas & 0,13 & 0,37 & 1 & 2,9 & 1,00 & 0,76 & 4,29 & 1,07 \\
\hline Cassytha americana & 0,13 & 0,37 & 1 & 2,9 & 1,00 & 0,76 & 4,29 & 1,07 \\
\hline TOTAL & 33,50 & 100 & 34 & 100 & 130,83 & 100 & 400 & 100 \\
\hline
\end{tabular}

Den: densidade (pl/m-22); Fre: frequência; Abu: abundância, DenR: densidade relativa (\%); FreR: frequência relativa (\%); AbuR: abundância relativa (\%); IVI: índice de valor de importância; IR: importância relativa (\%).

Ao conhecer os índices fitossociológicos, se consegue analisar o impacto que os sistemas de manejo e as práticas feitas na área, influenciam a dinâmica de crescimento e ocupação de comunidades, favorecendo ou prejudicando determinada espécie de planta daninha na flora infestante (Pitelli, 2015).

Um dado relevante foi o aparecimento de uma nova espécie, a Pariana sp. para os índices de abundância (Abu) e abundância relativa (AbuR), no qual obteve valores idênticos ao $R$. cephalotes de 4 e 11,8\% nestes itens, respectivamente (Tabela 4). Contudo esta espécie Pariana sp não foi relevante nos demais índices avaliados anteriormente.

\section{Florescimento}

Nesta época de avaliação as árvores de bacuri estavam em pleno florescimento. As espécies mais relevantes nesse estágio fenológico foram a Rhynchospora cephalotes, Dimerocostus strobilaceus e Heliconia psittacorum, atingindo altos valores em todos os índices (Tabela 5).

Os maiores valores dos índices de frequência e abundância foram representados por diferentes espécies, sendo Eugenia punicifolia na frequência e frequência relativa com 4 e 15,38\% respectivamente, já para a abundância e abundância relativa a espécie Rhynchospora ciliata obteve altos valores sendo 13 e 12,98\%. Contudo a espécie H. psittacorum obteve a mesma quantidade que a $R$. ciliata, sendo as mais importantes neste índice.

As três espécies mais importantes $R$. cephalotes, $D$. strobilaceus e H. psittacorum, obtiveram valores semelhantes nos índices de densidade (Den), variando de 3,63 a 4,88\% e no índice de valor de importância (IVI), oscilando de 50,68 a 66,88.

Novamente a espécie $R$. cephalotes, liderou a importância relativa (IR) (16,72\%), sendo a mais importante 
Tabela 5 - Descrição dos índices fitossociológicos da comunidade infestante, na época de florescimento dos bacurizeiros, Amazônia Oriental - PA

\begin{tabular}{|c|c|c|c|c|c|c|c|c|}
\hline Espécies de plantas daninhas & Den & $\begin{array}{c}\text { DenR } \\
(\%)\end{array}$ & Fre & $\begin{array}{c}\text { FreR } \\
(\%)\end{array}$ & Abu & $\begin{array}{c}\text { AbuR } \\
(\%)\end{array}$ & IVI & $\begin{array}{l}\text { IR } \\
(\%)\end{array}$ \\
\hline Rhynchospora cephalotes & 4,5 & 16,22 & 3 & 11,54 & 12 & 11,98 & 66,88 & 16,72 \\
\hline Dimerocostus strobilaceus & 3,63 & 13,06 & 3 & 11,54 & 9,67 & 9,65 & 61,40 & 15,35 \\
\hline Heliconia psittacorum & 4,88 & 17,57 & 3 & 11,54 & 13 & 12,98 & 50,68 & 12,67 \\
\hline Eugenia punicifolia & 4,5 & 16,22 & 4 & 15,38 & 9 & 8,99 & 44,66 & 11,16 \\
\hline Ischnospihon obliquus & 2,13 & 7,66 & 2 & 7,69 & 8,5 & 8,49 & 35,60 & 8,90 \\
\hline Rhynchospora ciliata & 1,63 & 5,86 & 1 & 3,85 & 13 & 12,98 & 33,09 & 8,27 \\
\hline Endlicheria paniculata & 2,13 & 7,66 & 2 & 7,69 & 8,5 & 8,49 & 24,29 & 6,07 \\
\hline Misanteca mahuba & 1 & 3,60 & 1 & 3,85 & 8 & 7,99 & 19,96 & 4,99 \\
\hline Egeria najas & 0,75 & 2,70 & 3 & 11,54 & 2 & 2,00 & 18,05 & 4,51 \\
\hline Borreria cymifolia & 1,13 & 4,05 & 2 & 7,69 & 4,5 & 4,49 & 17,60 & 4,40 \\
\hline Euphorbia heterphylla L. & 0,75 & 2,70 & 1 & 3,85 & 6 & 5,99 & 14,35 & 3,59 \\
\hline Rotala ramosior & 0,75 & 2,70 & 1 & 3,85 & 6 & 5,99 & 13,44 & 3,36 \\
\hline TOTAL & 27,75 & 100 & 26 & 100 & 100,17 & 100 & 400 & 100 \\
\hline
\end{tabular}

Den: densidade (pl/ $\left.\mathrm{m}^{-2}\right)$; Fre: frequência; Abu: abundância, DenR: densidade relativa (\%); FreR: frequência relativa (\%); AbuR: abundância relativa (\%); IVI: índice de valor de importância; IR: importância relativa (\%).

nesta avaliação. Vulgarmente chamada de capim assapê, essa planta daninha de difícil controle é infestante de culturas de todo o Brasil. Sendo o gênero Rhynchospora, considerado o mais importante entre as Cyperaceas, em virtude do seu número de espécies e abundância de indivíduos que ocorrem em diferentes ambientes (Abreu Ferreira e Eggers, 2008). O clima quente foi proeminente, propiciando o desenvolvimento de plantas pertencentes ao grupo C4 na eficiência fotossintética, o que possivelmente influenciou o aparecimento e desenvolvimento da espécie Rhynchospora cephalotes, a qual apareceu em todas as avalições como uma das três mais importantes.

As plantas C4 apresentam uma elevada adaptabilidade em ambientes com alta luminosidade e baixa disponibilidade hídrica, isso ocorre devido a fixação de carbono ocorrer através de moléculas de $\mathrm{CO}_{2}$ presentes em câmaras de ar existentes nos tecidos das folhas, o que evita a abertura dos estômatos e reduz a perda de água por transpiração (Santos et al., 2015).

\section{CONCLUSÃO}

A composição da flora infestante não foi idêntica em todas as avaliações durante o período experimental. Contudo as espécies Rhynchospora cephalotes, Heliconia angustia e Eugenia punicifolia foram as mais expressivas, estando presente na maioria dos índices, em todas as avalições.

\section{LITERATURACITADA}

BRIGHENTI, A.M.; DE OLIVEIRA, M.F. Biologia de plantas daninhas, 2011. In: https:// www.alice.cnptia.embrapa.br/bitstream/doc/904874/ 1/Biologiaplantasdaninhas.pdf (acesso em 10 de janeiro de 2017).

CARVALHO, L.B. et al. Interferência e estudo fitossociológico da comunidade infestante em beterraba de semeadura direta, 2008. In: http:// www.scielo.br/pdf/pd/v26n2/a05v26n2 (acesso em 11 de janeiro de 2017).

DE CASTRO, C.E.F. et al. Avaliação de espécies de Costaceae para uso ornamental, 2011a. In: https://ornamentalhorticulture.emnuvens.com.br/ rbho/article/view/719 (acesso em 13 de fevereiro de 2017).

DE CASTRO, C.E.F. et al. Helicônias brasileiras: características, ocorrência e usos, 2011b. In: https://ornamentalhorticulture.emnuvens.com.br/ rbho/article/view/725/532 (acesso em 13 de fevereiro de 2017).

FERREIRA, C.G.T. et al. Poaceae da Estação Ecológica do Seridó, Rio Grande do Norte, Brasil, 2009. In: http://www.scielo.br/ scielo.php?script=sci_arttext\&pid=S2236$89062009000400008 \& \operatorname{lng}=$ pt\&nrm=iso (acesso em 25 de fevereiro de 2017). 
ABREU FERREIRA, P.M.; EGGERS, L. Espécies de Cyperaceae do Centro de Pesquisa e Conservação da Natureza Pró-Mata, município de São Francisco de Paula, RS, Brasil, 2008. In: https://

www.researchgate.net/profile/

Pedro_Maria_Abreu_Ferreira/publication/

262708182_Cyperaceae_species_of_the_Centro_de_Protecao_e _Conservacao_da_Natureza_ProMata_Sao_Francisco_de_ Paula_municipality_Rio_Grande_do_Sul_State_Brazil/ links/55f0cad008ae0af8ee1d3290/Cyperaceaespecies-of-the-Centro-de-Protecao-e-Conservacaoda-Natureza-Pro-Mata-Sao-Francisco-de-Paulamunicipality-Rio-Grande-do-Sul-State-Brazil.pdf (acesso em 10 de março de 2017).

GAMA, J.C.M. Florística e Fitossociologia de Plantas Espontâneas em Comunidades Antropizadas do Cerrado em Minas Gerais, 2009. In: http://www.bibliotecadigital.ufmg.br/dspace/ bitstream/handle/1843/NCAP-8A8GNQ/ disserta_o_jord_nia_mac_do.pdf?sequence $=1$ (acesso em 11 de janeiro de 2017).

HOMMA, A.K.O. Extrativismo vegetal ou plantio: qual a opção para a Amazônia? 2012. In: http:// dx.doi.org/10.1590/S0103-40142012000100012 (acesso em 15 de dezembro de 2016).

HOMMA, A.K.O.; DE CARVALHO, J.E.U.; DE MENEZES, A.J.E.A. Bacuri: fruta amazônica em ascensão, 2010. In: http://

www.alice.cnptia.embrapa.br/alice/handle/doc/ 872367 (acesso em 15 de dezembro de 2016).

INMET - Instituto Nacional de Meteorologia. In: http://www.inmet.gov.br/sim/abre_graficos.php (acesso em 27 de fevereiro de 2016).

MACIEL, J.R.; OLIVEIRA, R.C.; ALVES, M. Padrões de distribuição das espécies de Paspalum L. (Poaceae: Panicoideae: Paniceae) ocorrentes em Pernambuco, Brasil, 2009. In: http:// www.scielo.br/scielo.php?pid=S01008404200900 $0300017 \&$ script $=$ sci_arttext\&tlng $=\mathrm{ES}$ (acesso em 25 de fevereiro de 2017).

SANDRE, A.A. et al. Ensino de Botânica: A Botânica no cotidiano, 2008. In: http:// www2.ib.usp.br/index.php?option=com_docman \&task=doc_download\&gid=58\&Itemid=98 (acesso em 08 de fevereiro de 2017).
OLIVEIRA, A.R.; FREITAS, S.P. Levantamento fitossociológico de plantas daninhas em áreas de produção de cana-de-açúcar, 2008. In: http:// www.scielo.br/pdf/pd/v26n1/a04v26n1 (acesso em 11 de janeiro de 2017).

PITELLI, R.A. O termo planta-daninha, 2015. In: http://www.scielo.br/scielo.php?pid=S0100835820 $15000300622 \&$ script=sci_arttext\&tlng=pt (acesso em 18 de dezembro de 2016).

REIS, P.A. Poaceae das formações florestais e do cerrado sentido restrito do Parque Nacional de Brasília-DF, Brasil, 2013. In: http:// repositorio.unb.br/handle/10482/17438 (acesso em 08 de março de 2017).

ROCHA, D.C.; RODELLA, R.A.; MARTINS D. Ocorrência de Commelina villosa como planta daninha em áreas agrícolas no Estado do Paraná-PR, Brasil, 2000. In: http://hdl.handle.net/11449/27936 (acesso em 15 de fevereiro de 2017).

SANTOS, C.S. et al. Levantamento fitossociológico de plantas daninhas na cultura da laranja, 2015. In: http://www.dca.uem.br/V4N2/06.pdf (acesso em 10 de março de 2017).

SAVÓIA, E.J.L. Potencial de Tradescantia pallida cv. Purpurea para biomonitoramento da poluição aérea de Santo André - São Paulo, por meio do bioensaio Trad - MCN e do acúmulo foliar de elementos tóxicos, 2013. In: http://www.teses.usp.br/teses/ disponiveis/5/5160/tde20062007154214/publico/ erianesavoia.pdf (acesso em 15 de fevereiro de 2017).

SILVA, A.A; JAKELAITIS, A.; FERREIRA. L.R. Prejuízo à vista. Cultivar grandes culturas, 2002. In: http://www.grupocultivar.com.br/ativemanager/ uploads/arquivos/artigos/gc40_prejuizo.pdf (acesso em 15 de fevereiro de 2017).

SOBRAL, M. et al. Myrtaceae. In: Forzza, R.C. et al. Lista de Espécies da Flora do Brasil, 2010. In: http:// floradobrasil.jbrj.gov.br/2010/FB010791 (acesso em 10 de fevereiro de 2017).

SOUZA, V.C.; LORENZI, H. Botânica sistemática: guia ilustrado para identificação das famílias de Angiospermas da flora brasileira, baseado em APG II, 2005. In: https://searchworks.stanford.edu/view/ 6525394 (acesso em 10 de março de 2017).

Recebido para publicação em 4/5/2018 e aprovado em 12/3/2019. 